\title{
OPEN
}

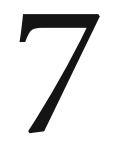

\section{The Future of Ageing - Stakeholder Involvement on the Future of Care}

\section{Marianne Barland, Pierre Delvenne and Benedikt Rosskamp}

\begin{abstract}
Barland et al. describe an example project showcasing the strengths of technology assessment methodology in structuring stakeholder dialogues in a cross-European context. The authors provide an in-depth account of the method design choices made and their underlying rationale. Beyond the buzzword, well-structured and transparent stakeholder dialogue can help to balance difficult issues of policy priority - in this case by balancing the contributions of technological innovation against social reorganization as a means of securing sustainable future health-care service for senior citizens. The article shows the added value of multi-site dialogues based in national debates but linked to the European policy development process.

Klüver, Lars, Rasmus Øjvind Nielsen, and Marie Louise Jørgensen, eds. Policy-Oriented Technology Assessment Across Europe: Expanding Capacities. Basingstoke: Palgrave Macmillan, 2016. DOI: 10.1057/9781137561725.0017.
\end{abstract}


Figuring out how we can cope with ageing societies is one of the grand challenges identified in the Lund Declaration. The demographic composition of the world is changing, and projections show that in the next 35 years the number of people over 60 years will double, while those aged 80 or older will quadruple. At the same time, the available workforce in the care sector will decrease to a point where the need for care will surpass the available resources. This development challenges existing health-care systems in Europe, and in order to have a sustainable system in the future, one needs to rethink policies related to health care.

The European Commission's 'Digital Agenda for Europe' pointed to technology as part of the solution for addressing the challenges raised by ageing society. The strategy states that new information and communication technology (ICT) capabilities could support ageing citizens, revolutionize health care and provide better public service. But barring the way to any easy technological fix are critical issues, which must be tackled to ensure a sustainable health-care system. Technology will likely be an integral part of such a system, but there will also be a need for substantial social and organizational change to reorganize health-care services in Europe.

To illustrate the value of stakeholder dialogues structured through TA methodology, PACITA organized a cross-European assessment experiment aimed at investigating how technological innovation along with social reorganization could contribute to creating sustainable health-care services for European seniors in the different societal situations of member states.

The project's goal was twofold: (1) to identify opportunities, challenges and barriers as well as policy options for the use of technology in the health-care sector and (2) to train and exchange knowledge on the method of scenario workshops among the project partners and, hence, to increase the national knowledge base for policy making. The result of the project was a series of policy options and recommendations.

\section{Framing the issue of technology and policy in Europe}

How or if technology is implemented in the care sector varies greatly among the European countries represented in PACITA, ${ }^{1}$ alongside a varied approach from policy makers. In order to map the terrain, the first tasks of the PACITA project on ageing societies were therefore to produce a policy status overview (Fitzgerald, 2014), presenting and comparing the different strategies put forward by policy makers in 
country. In the same way, a technology overview (Meidert and Becker, 2013) was made in order to map the technologies that are used in the European care sector today and to anticipate which technologies may play a role in the future of (health) care for senior citizens.

The technology overview showed that a variety of devices and technology are used in European health-care services today. However, implementation varies from country to country, and the range of technologies is increasing as their market potential is increasingly recognized by developers and investors. Most of the technology, which has already been implemented, belongs to what we may call 'first-generation telecare', such as alarm buttons and sensors. Some countries have already started using more complex technology, which includes the measurement of vital signs or two-way digital communication between patient and doctor to reduce the need for home visits or hospital appointments.

The variation of technologies is reflected at the policy level. Although all countries are facing the same challenges, they respond in quite different ways. Analysis of policy documents from the different countries involved in PACITA shows that the use of technology in care is starting to be recognized in some countries. However, there are large national differences in the way that it is interpreted as well as the perceived level of urgency in designing, addressing and implementing such policies. The analysis of policy documents also shows that there are a number of definitions used to describe telecare and home-based telemedicine. The differences are not only between countries but also within countries - for example, between official governmental reports and national stakeholders.

Technological developments are always difficult to predict, but the technology overview highlights some trends that probably will influence the distribution and implementation of technology in the health-care sector. Among these trends are smartphone and mobile solutions that would enable easier data collection and communication. Together with an increasing use of monitoring devices, digital assistants and a wide selection of apps, mobile health may become a reality in the near future. Data collection and big data analysis will increase and can be used for prediction and preventive work.

Just as important as technological development is the development of regional, national and European policies that address the various ways in which technologies could be integrated in health-care systems. Whether health authorities choose to encourage implementation or to stay passive will strongly affect future use. Private actors and industry will also play 
an important role as the potential of a flourishing market for health-care technology will affect policy making all over Europe. One of the overall conclusions reached in this mapping exercise is thus that long-term policies and strategies will be necessary in order to implement technology in a productive and responsible way.

\section{Engaging stakeholders in policy discussions}

There will always be actors that are affected positively or negatively by research, technological development and policy decisions. But often, actors that have a stake in the issues are not automatically consulted or included in the decision-making process, even though they are the ones that will live with the consequences of these decisions. This produces a risk that inappropriate technology may be developed or ineffective policy implemented. In order to avoid this situation, the PACITA project on ageing societies aimed at involving a diverse group of stakeholders to open the discussion to a variety of voices, different kinds of knowledge, perspectives, values and dilemmas.

The underlying argument that supports stakeholder involvement is that it can lead to better-informed policy decisions and more critical discussions about the topic at hand. Typical policy consultations often involve homogenous groups of experts that think along the same lines. Such homogeneity of opinion can weaken the democratic aspect of policy making because the discussion often will evolve around a limited view of the topic. Involving a broader and more balanced spectrum of actors makes the process more diverse and enables the creation of more multidimensional and resilient solutions. Additionally, when the concerned actors are included in the process, it can lead to an easier implementation of policy decisions as the involvement facilitates a stronger ownership of the decision-making process among the stakeholders, therefore allowing more robust decisions to be made.

A broadly recruited, heterogeneous group of stakeholders will have very different backgrounds and experiences with a given topic. We therefore developed future-oriented scenarios to give the stakeholders a common starting point for discussion. Using the scenario workshop method, the stakeholders engaged in forward-looking discussions and identified policy options on a given topic. The purpose of the scenarios is to make the participants more conscious of future developments and 
choices related to technology in society and to inspire critical reflection. Through such discussions, stakeholders may contribute to the development and identification of new visions and policy options based on their first-hand experience with the topic at hand.

\section{Creating scenarios for the future of ageing and new technology}

Society and policy makers are faced with many collective choices, and the latter need to handle sometimes conflicting priorities when developing their policies. The outcome and the implications of their choices may be difficult to anticipate. Our scenarios on ageing did not try to predict the future and did not purport to encompass all aspects of a possible future. Instead, they presented sharply distinct alternative futures that one might expect to arise from discrete policy choices, highlighting the challenges, dilemmas and conflicts that could occur in order to spur discussion.

It is a challenge to write up scenarios that are considered relevant for a broad group of countries and regions because of how diverse the reality of health-care systems and use of technology are. Immigration, distribution of technology and digital literacy are generally perceived

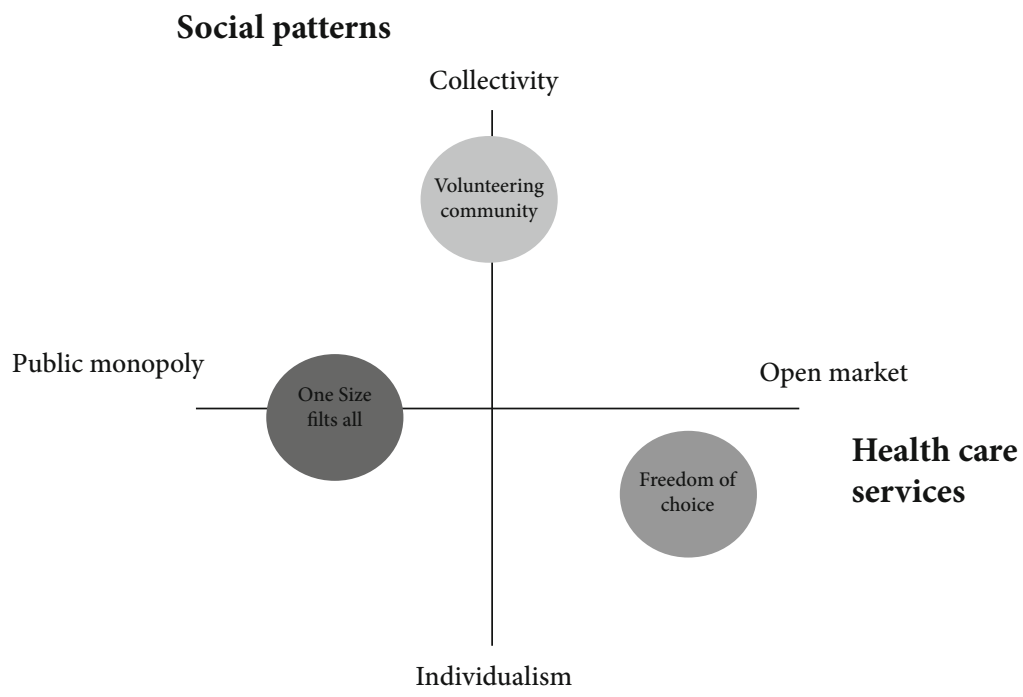

FIGURE 7.1 The PACITA scenarios for the future of ageing 
TABLE 7.1 Content of scenarios on the future of ageing

The PACITA scenarios on the future of ageing

One size fits all is based on the assumption of lack of labour in the future, and it describes a large-scale governmental initiative that uses technologies to make people more self-reliant. Everyone in need of care is offered a standard 'care kit' that consists of different assistive technologies. Seniors are encouraged to live at home as long as possible.

Freedom of choice is based on a new political system where incentives for care go directly to the user. This scenario furthermore describes a society where you can buy a great variety of health-care services and technology from the open market. Everyone in need of care is entitled to incentives and financial support depending on their individual health condition.

Volunteering community is based on utilizing volunteers as the key resource for the community and for each other. This community could include the senior citizens themselves, their relatives, organizations, neighbours, school kids and so on. The authorities' main responsibility is to mobilize the coordination of the volunteers.

very differently in different countries. Therefore, instead of dealing with concrete technological solutions, we structured ours along two axes of 'social patterns' and 'organization of health-care services'. This more generic approach ensured that all countries could recognize parts of their own reality, but at the same time the scenarios told stories that stirred debate among the stakeholders.

The three scenarios, 'One size fits all', 'Freedom of choice' and 'Volunteering community' describe futures where health-care services are organized and financed in different ways and where health-care service may be affected by increased government control, a stronger private sector or a better organized volunteer community.

\section{Designing national scenario workshops}

The main activity in the PACITA project on ageing was ten national scenario workshops organized by the project partners. They all followed the same method: ${ }^{2}$ critiquing, discussing and giving feedback on the three scenarios, and in the end formulating visions and recommendations for policy makers. The participants at the workshops were broad groups of stakeholders from academia, the health-care sector, policy makers, public administration, industry and senior organizations.

The results from the workshops were collected in national reports that describe the response to the scenarios and the future recommendations. ${ }^{3}$ 
While all countries agreed that there is potential in using technology in the health-care sector, several differences became obvious when it came to describing possible barriers and challenges related to implementation and use. These national peculiarities reflected cultural and social aspects in the respective countries and regions and also reflected to what degree the debate about technology and ageing had been prominent or not. In this way, the differences across countries reflected different values and worldviews with regard to the use of technology in health care and social innovations. In many countries, there were no established arenas beforehand where stakeholders could come together and discuss current and future policy developments. In this way, our experiment was very successful in terms of facilitating dialogue and knowledge exchange between stakeholders that were otherwise unconnected.

\section{Recommendations for future sustainable health-care services}

The policy report is structured by five policy issues that were recognized as particularly important at the national workshops, with related policy options and recommendations (summarized in Table 7.2 below).

Technology is considered an important element in future health care by many actors, such as the EU and national or regional authorities all over Europe. The stakeholders involved in the PACITA project support this, but they stressed the importance of broadening the debate and to also look at social and organizational innovation.

\section{Broadening the knowledge base for policy making}

Societal challenges that involve new technology can often be perceived as complex and difficult to grasp. The experience from the PACITA project on ageing clearly shows that involving a broad group of stakeholders in discussions can help identifying opportunities, challenges and barriers related to the future of health care and the implementation of new technology. The stakeholders' hands-on knowledge and diverse areas of expertise provided important insights that would not necessarily have been identified by the homogenous expert groups traditionally involved in policy-making processes. 
TABLE 7.2 Policy recommendations produced by participating stakeholders

\begin{tabular}{|c|c|}
\hline Policy issues & Policy options and recommendations \\
\hline $\begin{array}{l}\text { Support individual } \\
\text { needs, self- } \\
\text { determination and } \\
\text { autonomy }\end{array}$ & $\begin{array}{l}\text { - Enable seniors to live independently and securely at home. } \\
\text { - Promote informed decisions. } \\
\text { - Improve ageing literacy: prepare seniors for ageing well. } \\
\text { - Introduce a system for assessing individual needs. }\end{array}$ \\
\hline $\begin{array}{l}\text { Provide basic care for } \\
\text { everyone }\end{array}$ & $\begin{array}{l}\text { - Develop long-term strategies that responsibly introduce } \\
\text { technology and ensure basic care. } \\
\text { - Create arenas and networks for knowledge exchange. } \\
\text { - Introduce means for prevention of unacceptable } \\
\text { consequences, such as loneliness and isolation. }\end{array}$ \\
\hline $\begin{array}{l}\text { Participation in society } \\
\text { and voluntary work }\end{array}$ & $\begin{array}{l}\text { - Establish a mentality and culture for volunteering. } \\
\text { - Define tasks and establish trust for participation in care. } \\
\text { - Provide incentives for volunteering. } \\
\text { - Mobilize senior citizens as active contributors. }\end{array}$ \\
\hline $\begin{array}{l}\text { Public-private } \\
\text { collaboration }\end{array}$ & $\begin{array}{l}\text { - Stimulate service innovation, research and development } \\
\text { of telecare and telehealth. } \\
\text { - Define infrastructural means and standards. } \\
\text { - Require universal design in all services and products. } \\
\text { - Stimulate and ensure user-participation in R\&I. }\end{array}$ \\
\hline $\begin{array}{l}\text { Organization, regulation } \\
\text { and education }\end{array}$ & $\begin{array}{l}\text { - Protect privacy. } \\
\text { - Include technology in education and training of health- } \\
\text { care personnel. } \\
\text { - Open up for new roles in the health sector. } \\
\text { - Focus on dialogue and transparency. }\end{array}$ \\
\hline
\end{tabular}

Involvement of carefully selected diverse stakeholder groups is also a way to make policy decisions more democratic, robust and socially acceptable. Involving relevant stakeholders in the process can give them ownership of the process and increases the chances for both adapted policy prescriptions and the development of relevant products actually meeting users' needs. This in turn can make implementation processes easier.

\section{Cross-European stakeholder involvement}

The method of scenario workshops has until now mainly been used in national contexts. Using the method in a cross-European manner proved challenging to some degree, but it was also beneficial to the project results and the embedded potential of the method.

In the preparation of the scenarios, it proved challenging to write scenarios that were both general enough to feel relevant for all participating countries and at the same time specific enough to provoke discussion. 
Scenarios that are too general would not have contributed to the desired discussion, while making them too specific would have made it difficult to relate to the range of ethical and social dilemmas to be dealt with. But the cross-European approach proved to give significant added value compared with the more common alternative, which is a series of isolated, national debates taken without much synchronicity. The scenarios created discussion that had the same starting point but that moved in different directions based on national differences in experience, organization and financing of health-care services and national/regional culture, policy preferences and worldviews. The national reports describe dilemmas, barriers and solutions that are grounded in a specific national or regional context but that are highly relevant for policy makers all over Europe.

Realizing that all countries face the same challenge, learning from each other, exchanging experiences and identifying European examples of best practices are starting points for the future of knowledge-based policy making within and across Europe. The method of scenario workshops proved suitable to a cross-European context, and the format of separate national activities that were linked by taking the scenarios as a common starting point for discussion created a common frame for the dialogues which ensured the comparability of the results that were collected at the regional or national level. The PACITA workshops produced important insights for national and regional, as well as European, policy making. But it also highlighted the importance of independent and diverse policy advice, an opinion that was emphasized by all the involved participants. The coming together of stakeholders facilitates not only a knowledge exchange but also knowledge production for the future.

\section{Notes}

1 The involved partners represented Austria, Bulgaria, Catalonia (Spain), the Czech Republic, Denmark, Hungary, Ireland, Norway, Switzerland and Wallonia (Belgium).

2 Barland (2013).

3 Country reports are available at www.pacitaproject.eu.

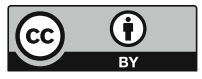
copy of this license, visit https://creativecommons.org/version4 